\title{
Tittle: The relationship between resilience and quality of life in patients with a
}

\section{drainage enterostomy.}

Autors: Maria Dolores Temprado Albalat, Pedro García Martínez, Rafael Ballester Arnal y Eladio Joaquón Collado Boira

\section{ABSTRACT}

Introduction. Impact and adjustment to a drainage enterostomy are measured mainly through health indicators. Objective. To investigate the relationship between resilience and adaptation to the placement of a drainage enterostomy. Methodology. Prospective observational study with a sample of 125 patients (64 men / 36 women) with a temporary or permanent drainage enterostomy and a mean age of 66.72 years. Results. High quality of life (mean 80.5) and resilience (mean 79.57) scores and a positive relationship between both were found. There seems to be a positive relationship with general QL and HRQL. The logistic regression model shows that the main predictor as regards HRQL is resilience.

KEYWORDS: Colon, ostomy, quality of life, resilience, chronic disease, enterostomy

\section{INTRODUCTION}

In recent decades the concept of health has undergone important changes, chronic diseases becoming the main health problem. Advances in science and technology and the aging of the population are two factors that have led to an increase in the number of people that live with chronic pathologies (INE, 2013; Vera, et al., 2014). These include patients with colon cancer or inflammatory bowel disease, where intestinal drainage 
ostomy can often be found as the main consequence of their treatment. As proof of this increase, recent studies have shown that in Spain there are about 70,000 people with ostomies and the incidence is growing at a rate of around 13,000 new cases per year (Cancio López, Coca, Fernandez, Serrano, \& Garcia, 2014).

In order to study how these patients adjust to their disease it is necessary to understand that intestinal stoma surgery is a procedure in which the compromised part of the intestine is removed and a conduit is constructed through the intestinal wall to allow faecal matter to be discharged.

This surgical intervention is, therefore, an invasive procedure that often gives rise to digestive and hydroelectrolytic alterations. Coping abilities must therefore be developed to help patients deal with this situation of great stress and discomfort (Mathis, Boostrom, \& Pemberton, 2013). Moreover, chronic diseases, as is the case of having an enterostomy, are defined as diseases that are prolonged in time, do not resolve spontaneously and are rarely fully cured (Vilhena, et al., 2014). Hence, the chronic suffering of these patients is related to symptoms of disability that lead to different degrees of dependency and require long-term treatments, including initiatives aimed at helping patients to learn to live with the ensuing limitations and actions designed to control the clinical manifestations, as well as to prevent complications (Barbado, Blanco, \& Blasco, 2013). Furthermore, having a drainage enterostomy entails an important behavioural shift in one's daily routines, in addition to having to incorporate within one's daily life a series of new behaviours related to personal care and hygiene that require a great deal of time and dedication. These conditions generate a high degree of stress and discomfort, with a large emotional burden that alters social aspects such as family relationships, friendships or leisure activities, among others 
(Weston, \& Jackson, 2014). All these changes therefore require a period of adaptation or adjustment to the new situation, in those patients who are able to do so.

Health professionals measure adjustment to a disease and make health decisions based on a series of health indicators. Hence, the quality of life of patients with a drainage ostomy is taken as one of the most important health indicators when it comes to predicting the level of psychological adjustment to the new condition (Black, 2010; Campillo, \& Zaragoza, 2014; Dabirian, Yaghmaei, Rassouli, \& Tafreshi, 2011; Golicki, Styczen, \& Szczepkowski, 2013; Hu et al., 2014; O'Connor, 2005; Shun, et al., 2011). It should be remarked that quality of life (QL) refers to the subjective perception of important aspects of a person's life; that is to say, it has to do with the significance that people attribute to it and in this sense it is a social construct. More particularly, Health-Related Quality of Life (HRQL) is the aspect of quality of life that refers specifically to the health of a person and is used to designate the particular outcomes of clinical evaluation and therapeutic decision-making (Fernández, Fernández, \& Cieza, 2010; Mezzich, Cohen, Ruiperez, Banzato, \& Zapata-Vega, 2011). Many studies conducted with patients with a drainage enterostomy use general quality of life as a health indicator (Anaraki, et al., 2012; Geraldo, de Almeida, \& Silveira, 2014; Krouse, \& Grant, 2003; Marquis, Marrel, \& Jambon, 2003). An increasing number of studies and researchers, however, are creating and using instruments to measure the specific $Q L$ for the condition of having a drainage enterostomy (Baxter et al., 2006; Marquis, et al., 2003; Olbrisch, 1983; Prieto, Thorsen, \& Juul, 2005; Sprangers, Te Velde, \& Aaronson, 1999). These studies have shown that the quality of life of patients who have a drainage enterostomy is compromised (Cancio López et al., 2014; Grant et al., 2007). They have also revealed that the financial part of their quality of life is especially affected (Maydick, 2014). Other studies conclude that the social part is the most 
strongly disrupted, although the psychological part and management of the ostomy are also compromised, along with sexual relationships (Anaraki, et al., 2012; Liao \& Qin, 2014; Popek, et al., 2010). Among the variables that have been seen to have a greater effect on the perception of the quality of life, those considered to have the strongest impact on the perception of HRQL are: suffering some kind of complication, leaks and smells, clothing and change of image, and sleep disorders (Canova, Giorato, Roveron, Turrini, \& Zanotti, 2013; Jansen, et al., 2015; Liao, \& Qin, 2014; Person, et al., 2012).

In this process of adapting to new stressful situations, as is the case of having a drainage enterostomy, it has been quite clear for many years that there are individual differences in the way people adapt to them. Understanding these differences in adaptation is addressed on an increasingly frequent basis from the resilience approach (Waaktaar, \& Torgersen, 2010).

All the definitions of the construct of resilience put forward by researchers in studies on resilience and health share a number of common points that are important when it comes to relating this construct with the health process. These common points are: for resilience to develop, it is necessary to have first undergone an adverse event; it is the ability to maintain good levels of health functioning or to return to normality despite adversity; and lastly, factors from different systems are considered to be involved in resilience or it is understood as a dynamic process as opposed to a set personality trait (Johnston ${ }_{2}$ et al., 2015). Hence, this conception gave rise to a strong interest in studying resilience and examining its relationship with adjustment to chronic disease. Resilience can therefore be defined as the capacity of persons exposed to traumatic events to maintain relatively healthy and steady levels of psychological and physical functioning, as well as the capacity to generate positive experiences and emotions ( $G$ Bonanno ${ }_{1}$ et al., 2008). In their studies 
conducted on people with severe diseases, these authors identified four prototypical patterns or long-term responses that most people present as in answer to the stress of suffering from such a disease, namely, the resilience, chronic dysfunction, recovery and delayed reaction patterns (Morin, Galatzer-Levy, Maccallum, \& Bonanno, 2017). They also highlighted the difference between recovery and resilience. In their view, recovery from traumatic events is associated with an increase in the number of psychological problems over a period of time, and the resilience pattern is characterised by seeking social support, getting on with life and accepting circumstances with hope (G Bonanno, \& Diminich, 2013; Garcia-Dia, DiNapoli, Garcia-Ona, Jakubowski, \& O’Flaherty, 2013; Ho, Ho, Bonanno, Chu, \& Chan, 2010).

Of special importance is the understanding of resilience and adjustment to disease in patients who have been diagnosed with some kind of cancer. As a consequence of a diagnosis that is seen to be potentially fatal, the levels of tension or stress rise in healthy persons, in addition to finding themselves with the need to cope with many changes in their life and to continue to adapt to them (Hou, et al., 2010; Molina, et al., 2014). The results of studies carried out on patients with cancer can be considered in the same line, since they show that resilience is positively correlated with health indicators such as emotional health and well-being (Lamond, et al., 2008), life satisfaction, self-esteem, social adaptation (Benetti, \& Kambouropoulos, 2006; Peng, et al., 2012) and social support (Clauss-Ehlers, 2008; Connor, \& Davidson, 2003; Van Dick, Ketturat, Häusser, \& Mojzisch, 2017). In contrast, negative correlations have been found with negative emotions (Burns, \& Anstey, 2010), depression and anxiety (Kawasaki, Uchinuno, Arao, Kobayashi, \& Otsuka, 2011; Peng, et al., 2012), vulnerability to stress (Min, et al., 2013), and distress and emotional stress (Ho, et al., 2010). 
Many studies provide scientific evidence that resilience is predictive of a lower level of distress, better adjustment and improved quality of life in patients with a chronic disease (Bowen, Morasca, \& Meischke, 2003; Costanzo, Ryff, \& Singer, 2009; Haase, Kintner, Monahan, \& Robb, 2014; Harris, et al., 2010; Lee, et al., 2007; Liu, Wang, \& Li, 2012; Molina, et al., 2014; Ong, Bergeman, \& Boker, 2009; Rowland, \& Baker, 2005; Strauss, et al., 2007; Temprado, Agut, \& Collado, 2017; Wu, et al., 2015). In this study we inquired into the relationship between resilience and quality of life factors ( $Q L$ and $H R Q L)$ in patients with a drainage enterostomy. The objective of our research is to analyse the impact of a chronic process, as is the case of a drainage enterostomy, on the HRQL of these patients, and to determine whether resilience has some kind of positive or negative relationship with it. Similarly, it also intends to analyse what types of clinical or sociodemographic variables have some kind of influence upon it. We believe that this knowledge and the results of this study can be very useful to carry out interdisciplinary intervention programmes aimed at improving resilience and self-care that would limit the occurrence of complications and improve the quality of life of these patients.

\section{METHOD}

We designed a multicentre correlational cross-sectional study to be conducted with colo/ileostomised patients over a period of three months, in hospitals with a digestive surgery service and a stoma therapy nursing unit in the province of Castellón. 
Inclusion and exclusion criteria

Inclusion criteria. Participants in the study had to be of legal age. Following a criterion established in previous studies on the adjustment of patients with an enterostomy (De Frutos, et al., 2011), they had to be colo/ileostomised patients with an enterostomy who had completed a post-surgery adaptation period of at least 3 months.

Exclusion criteria. Both patients in the terminal phase of their disease and those who had an insufficient command of Spanish were discarded from the study. Neither were patients with cognitive ability deficit included in it.

\section{Ethical aspects.}

The decision rights, anonymity and confidentiality of the participants were safeguarded at all times, respecting the ethical principles described in the Belmont report and the Nuremberg code.

To be able to gain access to the sample, it was first necessary to obtain permission from two CRECs (Research Ethics Committees) and authorisation from the management committees of the four hospitals in the health department in which the study was conducted.

In order to comply with current data protection legislation, the study was completely anonymous and the patients were coded on being incorporated into the study. Hence, at no time do any data appear that could be used to identify them. 


\section{Participants and procedure}

The initial sample consisted of a total of 185 patients who had had a drainage enterostomy for more than three months. After applying the inclusion criteria, the final sample included in the study consisted of 125 patients ( $n=64$ males and $n=36$ females).

As can be seen in Table 1, their ages ranged from 36 to 87 years old, with a mean age of 66.72 years $(S D=11.85)$. Of these, $85.6 \%$ were patients diagnosed with colon cancer, $7.2 \%$ of them had been diagnosed as suffering from an intestinal inflammatory disease (i.e. Crohn's disease or ulcerative colitis), 3\% presented a diagnosis of diverticulitis and the remaining $4.2 \%$ had undergone surgery due to other causes (i.e. endoscopic perforations, traumatic injury resulting from a road accident and intestinal infarction). With respect to the type of enterostomy, the majority of them had a colostomy (81.6\%) versus $18.4 \%$ who had an ileostomy. Most of the patients $(80 \%)$ reported being autonomous when it came to caring for their stoma and only $16.8 \%$ of them performed irrigations on a regular basis. $83.2 \%$ of the patients with an enterostomy reported never having had any kind of complication with it.

\section{INSERT TABLE 1}

Instruments and measurements

Demographic and basic medical information.

The researchers collected sociodemographic variables through personal interviews with patients (sex, age, reference hospital, marital status, studies, labour activity, number of children and economic income) and clinical variables (date of the surgical operation, medical diagnosis, type of ostomy, whether it was temporary or permanent, stoma level, 
irrigations, autonomy in stoma care or stoma-related complications) were obtained from each patient's medical history. The questionnaires used in the present study were administered by the two main researchers, a psychologist and a nurse, with unified criteria, in personal interviews lasting between 45 and 60 minutes conducted in the respective hospitals. The appointments were arranged previously by telephone, after informing the patients of the objective of the study.

Resilience. This was measured by means of the Spanish version of the CD-RISC, translated from the original English by Bobes and colleagues (Bobes, et al., 2001). The scale consists of 25 items measured by means of a Likert-type scale that ranges from 0 (Not at all) to 4 (Nearly always). The exploratory factor analysis performed by Connor and Davidson (2003) identified five factors that they called (1) Personal competence, high standards, and tenacity; (2) Trust in one's instincts and tolerance of negative affect, and strengthening effects of stress; (3) The positive acceptance of change, and building secure relationships; (4) Control; and (5) Spiritual influences. The range of the scale is from 0 to 100. No cut-off point was established for it and, thus, the higher the score is, the higher the person's level of resilience is.

General quality of life. This was measured by means of the Quality of Life Index-Spanish Version (QLI), which consists of 10 items each corresponding to a general quality of life indicator that are measured on a Likert-type response scale that ranges from 1 (Poor) to 10 (Excellent). These indicators are physical well-being, psychological and emotional wellbeing, self-care and independent functioning, occupational functioning, interpersonal functioning, social-emotional support, community and services support, personal fulfilment, spiritual fulfilment and overall perceived quality of life (Mezzich, et al., 2011). The range of 
the scale is from 0 to 100 . No cut-off point was established for it and, thus, the higher the score is, the higher the person's level of QL is.

Specific quality of life for patients with an enterostomy, or HRQL. This was measured by means of the Stoma-QOL (Quality of Life Questionnaire for patients with colostomy or ileostomy) (Prieto, et al., 2005). The questionnaire provides qualitative indicators that express the impact on quality of life and patient satisfaction. It consists of 20 questions with a Likert-type scale of four answers that are rated with a score of 1 to 4 . The final score that was calculated gives us a percentage of $80 \%$, so we must add $20 \%$ to the total to achieve a tabulation of $100 \%$. From this total, three levels of measurement were considered: good quality of life (result of $70-100 \%$ ), moderate quality of life (result of 30 $70 \%)$ and poor quality of life (result of $0-30 \%)$.

\section{Data analysis}

To adapt the measuring instruments referring to resilience and quality of life to this sample of patients we followed the indications given by George and Mallery (2003) with regard to the values of the Cronbach's alpha coefficient (Excellent $>.9$, Good .8- .89, Acceptable $.7-.79$, Questionable $.6-.69$, Poor .5 - .59, and Unacceptable < .5). Confirmatory Factor Analysis (CFA) was also performed by Structural Equation Modelling (SEM) using EQS 6.1 and following the robust indices. Thus, the model was considered to fit when the Satorra-Bentler $\mathrm{X}^{2}$ was not significant $(\mathrm{p}=.05)$, the BB-NFI, BB-NNFI, CFI and IFI were higher than .9 (if the NFI is not higher, the NNFI must be) and the RMSEA was below .08 (Herrero, Jara, \& Rosel, 2011).

The following statistical analyses were performed with the software package SPSS v23. The level of statistical significance required was $5 \%(p=.05)$. 
A univariate descriptive analysis was performed for both the sociodemographic and the clinical variables. The continuous variables are therefore described by measures of central tendency and standard deviation, and frequencies and percentages are used for the categorical variables.

For the correlation or bivariate analyses, first the normality of the quantitative variables was analysed with the Kolmogorov-Smirnof test in order to determine whether parametric or non-parametric tests should be used. For the non-parametric tests, the Mann-Whitney $U$ or the Kruskal-Wallis $\mathrm{H}$ were obtained. In the case of the parametric tests, an Independent samples t-test was conducted with variables that only had two categories or levels, whereas a one-factor Analysis of Variance (ANOVA) was performed for variables with more than two categories or levels. In the cases in which the ANOVA revealed significant differences in the comparisons for variances, a Bonferroni Post-Hoc test was conducted to determine which pairs of categories or levels had significant differences between them. In both the Student $t$ and the ANOVA tests the null hypothesis that the population variances are equal (variance homogeneity) was tested by means of the Levene test, and the study proceeded accordingly.

Lastly, and in order to study the relation between variables and identify the predictive value of the variables in the perception of the quality of life related to the particular health problem under study (HRQL), a multiple regression analysis was performed following the stepwise method. 


\section{RESULTS}

Adaptation of the measuring instruments (Confirmatory Factor Analysis)

Adaptation of the CD-RISC by Connor and Davidson (2003) and translated into Spanish by Bobes and colleagues (Bobes, et al., 2001). This instrument was adapted to the study sample by means of CFA followed by the corresponding SEM. This resulted in a questionnaire consisting of 17 items with a one-factor structure (Satorra-Bentler $x^{2}=.0488$, BB-NFI=.709, BB-NNFI=.913, CFI=.926, IFI=.930, RMSEA=.043). It also had a Cronbach's alpha coefficient that could be considered as Good $(\alpha=.836)$.

Adaptation of the Quality of Life Index-Spanish Version (QLI) (Mezzich, et al., 2011). This instrument was also adapted to the study sample by means of CFA and then the corresponding SEM. This resulted in a questionnaire consisting of 9 items with a onefactor structure (Satorra-Bentler $X^{2}=.0 .2455$, BB-NFI=.902, BB-NNFI=.924, CFI=.955, $\mathrm{IFI}=.957, \mathrm{RMSEA}=.075)$. It had a Cronbach's alpha coefficient that could be considered as Good $(\alpha=.851)$.

Adaptation of the Stoma-QOL (Quality of Life Questionnaire for patients with colostomy or ileostomy) (Prieto, et al., 2005). This instrument was also adapted to the study sample by means of FCA and its corresponding SEM (Satorra-Bentler $x^{2}=.0 .1436$, BB-NFI $=.745$, BB$\mathrm{NNFI}=.915, \mathrm{CFI}=.927, \mathrm{IFI}=.929, \mathrm{RMSEA}=.048)$. This resulted in a questionnaire consisting of 18 items with a two-factor structure that was different from the original. It had a Cronbach's alpha that was Good, both on the total scale $(\alpha=.860)$ and on two factors: factor 1 , or personal, $(\alpha=.793)$ and factor 2 , or social, $(\alpha=.802)$. 


\section{Descriptive Analyses}

Table 2 shows the descriptive analyses of Resilience (CD-RISC), the Quality of Life Index (QLI) and the Stoma-QOL after converting the scores of the data into scores out of 100 . The data related to resilience obtained in our study sample are low, in comparison to the resilience of the US population (80.7), but somewhat higher than the clinical population (71.8) or that with post-traumatic stress disorder (52.8) (Connor \& Davidson, 2003).

The authors of the instrument QLI do not propose any cut-off point, but we can see that the perception of quality of life presented by the mean of our sample is high. As regards

the Stoma-QOL, the level of quality of life perceived by the patients who participated in the study could be classified, according to the criterion of the authors, as Good (result of 70100\%) (Juul, \& Prieto, 2008).

In Table 2 we can also see the values of the Pearson correlation among the factors from the CD-RISC, QLI and Stoma-QOL scales. As expected, the results of the Pearson correlation show that there is a significant positive correlation between Resilience and both general Quality of life and HRQL.

\section{INSERT TABLE 2}

Relationship between the sociodemographic and clinical variables and the general and specific quality of life (HRQL)

We then inquired into the existence of significant differences in the level of perception of the general quality of life, specific health-related quality of life and resilience, depending on the different sociodemographic variables (i.e. gender, marital status, education, labour 
activity and income), as well as the clinical variables (i.e. diagnosis, type of ostomy, whether it was temporary or permanent, irrigations, complications and care autonomy).

As can be observed in Table 3 below, with regard to the sociodemographic variables, significant differences were only obtained in the cases of children and income. For children, significant differences were seen in specific quality of life for health and in resilience ( $P=0.001$; Mann-Whitney, in both cases). Patients with children presented better scores on HRQL (Stoma-QOL $\bar{x}=59.02)$ and resilience (CD-Risc $\bar{x}=57$ ) than those who do not have any children (Stoma-QOL $\bar{x}=49.30$ and CD-Risc $\bar{x}=47.53$ ).

With regard to income, significant differences were obtained on HRQL $(P=0.004$, KruskalWallis test) between patients with a level of income of 0 to 6,000 euros per year and those in the group with an annual income of between 6,000 and 12,000 euros. The group of patients that earned from 0 to 6,000 euros per year presented a higher mean score (Stoma-QOL $\bar{x}=59.74$ ) than the group with an annual income of 6,000 to 12,000 euros (Stoma-QOL $\bar{x}=52.33)$ (see Table 3).

Of the clinical variables, we obtained significant differences with the variables stoma complications and care autonomy. In the case of stoma complications, we observed that there were significant differences in the general quality of life (QLI) according to the Independent samples t-test $\left(\mathrm{t}_{d f}=1.968, \mathrm{p}=.05\right)$ and in the HRQL (Stoma-QOL) $(\mathrm{P}=0.011$; Mann-Whitney). Patients without any complications (QLI $\bar{x}=71.55$ and Stoma-QOL $\bar{X}=60.41)$ were the ones who presented better scores on general quality of life and HRQL with respect to the patients with complications (QLI $\bar{X}=64.10$ and Stoma-QOL $\bar{X}=51.73$ ) (see Table 3). 
With the variable care autonomy, the result of the Independent samples t-test showed that there were significant differences in general quality of life (QLI) ( $t_{d f}=2.651, p=.001$ ). Autonomous patients $(\mathrm{QLI} \overline{\mathrm{X}}=72.11$ ) presented better scores on general quality of life with respect to those who were not autonomous (QLI $\bar{x}=64.12)$ (see Table 3).

\section{INSERT TABLE 3}

Multiple linear regression analysis to predict the perception of quality of life

On performing the multiple linear regression, following the stepwise method, a significant regression equation was obtained in which the predictive variables were resilience and the presence of stoma-related complications. Hence, the higher resilience (main predicting factor) and the lower the percentage of complications (second predictive factor) are, the higher the overall score on specific health-related quality of life will be in patients who have undergone an enterostomy. This regression model predicts a variance of $24.4 \%$ with both variables (see table 4). According to the criterion proposed by Cohen (Cohen, 1988), in one-factor ANOVA models this factor would have to account for at least $10 \%$ of the variance of the dependent variable for the factor for it to be considered as having clinical relevance; a value of around .25 ( $25 \%$ of the explained variance) would indicate a high or clinically very relevant magnitude. Given these indications, we can say that our regression model has very high clinical relevance in explaining the health-related quality of life of patients who have undergone an enterostomy.

\section{INSERT TABLE 4}

\section{DISCUSSION}


On analysing the sociodemographic characteristics of the sample we can see that they are similar to those of other studies conducted with patients who have had an ostomy (Campillo \& Zaragoza, 2014; Cancio López, et al., 2014; Erlen, et al., 2011; Lin, Wu, \& Lee, 2009; Mahjoubi, Mirzaei, Azizi, Jafarinia, \& Zahedi-Shoolami, 2012; Marquis, et al., 2003; J Pittman, Kozell, \& Gray, 2009; Joyce Pittman, et al., 2008). In our sample we found that patients are mostly males (64\%) with a mean age of 66.72 years, which is consistent with the most important studies that have been conducted recently in our community health setting (Campillo, \& Zaragoza, 2014; Cancio López, et al., 2014), and coincides with the latest figures on the prevalence of colon cancer published by the Spanish Society of Medical Oncology (Ferlay, et al., 2013).

This allows us determine the typical profile of the patients in our sample: "Male patient between 65 and 75 years, diagnosed with colon cancer and with a permanent colostomy, married, retired, with primary education, and autonomous in the care of his stoma".

With respect to complications, the percentage of patients who do not present any stomarelated complications $(83.2 \%)$ is very similar to those of other studies conducted with ostomised patients, in which the percentage of patients who do not report any complications stands at around 80\% (Cancio López, et al., 2014; Liao, \& Qin, 2014). The patient's autonomy in terms of changing the device and stoma care is also important. In this regard, $79.8 \%$ of the patients in our study are autonomous when it comes to care, a figure that is higher than those obtained in similar studies conducted with Spanish populations, such as the Stoma Life study by Campillo in 2014 and the cost-effectiveness study of the Antae Institute carried out by Cancio López and colleagues, also in 2014; in both cases the percentage of autonomous patients was $75 \%$. 
On analysing the relation between resilience and both general and specific health-related quality of life, we find that there is a positive relationship with general quality of life, a result that is in agreement with many studies that provide scientific evidence showing that resilience predicts a lower level of distress, better adjustment, better quality of life and better levels of self-care in patients with a chronic disease (Bowen, et al., 2003; Costanzo, et al., 2009; Haase, et al., 2014; Liu, et al., 2012; Molina, et al., 2014; Ong, et al., 2009; Rowland, \& Baker, 2005; Strauss, et al., 2007; Wu, et al., 2015). In line with this, the results of our study also indicate that resilience is related to the specific level of quality of life in patients with a drainage enterostomy. These results suggest that people with a high level of resilience have a greater ability to grow in situations such as chronic illness, which probably allows them to adapt successfully to their new situation (Amar, Martínez, \& Utria, 2013; Ho, et al., 2010; Johnston, et al., 2015; Lam, et al., 2010; Luthar, Cicchetti, \& Becker, 2000; Molina, et al., 2014; Quiceno, \& Vinaccia, 2011; Wu, et al., 2015).

On testing for significant differences according to the sociodemographic and clinical variables in Quality of life, HRQL and Resilience, differences were only obtained in the variables children, income, stoma-related complications and being autonomous with regard to care. Significant differences were obtained with respect to the variable children, patients with children being those that presented better scores on HRQL and Resilience. This could be accounted for by the fact that they had greater social support than patients without children (Luo, Qin, \& Zheng, 2014). In the variable income, significant differences were observed between patients with income levels of 0 to 6,000 euros per year and those in the group that earned between 6,000 and 12,000 euros, those in the first group being the ones with better quality of life indices. This is a result that somewhat contradicts those of previous studies with ostomised patients, as the positive correlation obtained between 
income and quality of life was so clear that they concluded that interventions have to be geared towards helping to cover the costs arising from having an enterostomy (Krouse, et al., 2009; Maydick, 2014; Sun, et al., 2014). One plausible reason explaining why the results of our study do not run in the same line as others is that in our setting the public health service bears all the costs deriving from this condition and a recent study conducted on a Chinese population found that patients whose income has been modified as a consequence of the illness that led them to have an ostomy are the ones who report significantly poorer quality of life indices (Li, Rew, \& Hwang, 2012). Perhaps it would have been necessary to take into account whether the process and the condition of undergoing an enterostomy had given rise to a change in income in order to better understand this result.

With regard to the clinical variables, significant differences were only found in the variables complications and autonomous care, which we will go on to discuss in the following. With the clinical variable of presence or absence of complications, a significant deterioration of HRQL was seen in patients who present stoma-related complications. These results coincide with those from other studies (Campillo, \& Zaragoza, 2014; Cancio López, et al., 2014; Lin, et al., 2009; Simmons, Smith, Bobb, \& Liles, 2007) that also find a significant relationship with the presence of complications and a lower level of adjustment to the selfcare agency. All this seems logical in view of the discomfort resulting from the different complications, while a decline in the level of self-care also has an influence on vulnerability to suffering more complications.

As regards the variable care autonomy, it was found that patients who are autonomous in their stoma care display better general quality of life indices. This can be explained by the fact that the disease process and the subsequent ostomy is a devastating event, mainly 
due to all the changes involved in losing the functioning of the sphincter on being replaced by the drainage enterostomy. This entails the need to change daily life routines together with special care of both the stoma and all the material that must be used. As a result, patients who are autonomous with regard to their stoma care display a better adjustment to the chronic illness in a number of aspects, such as having a more proactive attitude, and improving their self-care agency and their perception of quality of life (Marina \& Angarita, 2014; Stephenson, Wagner, \& Bolton, 2013). Many authors therefore claim that it is essential to educate patients in the proper management of their ostomy with the aim of their becoming autonomous in caring for it (Di Gesaro, 2012; Ferlay, et al., 2013; O'Connor, 2005; Williams, 2012).

Finally, as regards the model that best predicts the perception of health-related quality of life (HRQL), the first is the variable resilience, followed by stoma-related complications and lastly income. We have already discussed the fact that both the variables stoma-related complications and income are important factors in the process of adjusting to the illness. As shown in this model, resilience is one of the variables that correlate with HRQL. Hence, and regarding the relationship between resilience and health indicators, many studies provide scientific evidence showing that resilience predicts a lower level of distress, better adjustment, better quality of life and higher levels of self-care in patients with a chronic illness (Bowen, et al., 2003; Costanzo, et al., 2009; Haase, et al., 2014; Liu, et al., 2012; Molina, et al., 2014; Ong, et al., 2009; Rowland, \& Baker, 2005; Strauss, et al., 2007; Wu, et al., 2015). In line with this and as noted above, the results of our study also show that resilience is related to the specific level of quality of life in patients with a drainage enterostomy. This would explain why people with a high level of resilience display the capacity to grow in the face of adversity, as is the case of suffering from a chronic illness, 
which leads them to a successful adaptation to their new situation (Amar, et al., 2013; Ho, et al., 2010; Johnston, et al., 2015; Lam, et al., 2010; Luthar, et al., 2000; Molina, et al., 2014; Quiceno, \& Vinaccia, 2011; Wu, et al., 2015). Resilience is therefore a mechanism that protects against disease-related processes that negatively affect physical and psychological health (Connor, \& Davidson, 2003) by improving people's psychological status (Lü, Wang, Liu, \& Zhang, 2014). The results of this study and previous research show that resilience can be a key factor in adjusting to stressing situations and thus to chronic diseases (Shi, Wang, Bian, \& Wang, 2015).

\section{Limitations of the study.}

Among the limitations of the research, it is necessary to mention that, although the methodology allows the main objectives to be reached, the number of patients included in the research is smaller than was initially estimated. The main reason for this was the low number of ostomised patients who met the inclusion criteria. Some patients complained about the duration of the personal interviews and others felt uncomfortable when dealing with intimate aspects related to their sexuality or hygiene related to the stoma and their intestinal eliminations. Additional studies should be performed with larger samples in order to generalise the results to ostomised patients as a whole.

\section{Practical Implications}

Finally, as a general conclusion from our study, we can say that in ostomised patients resilience plays an important role as a predictor of variables of adjustment to the disease, such as HRQL, together with clinical variables, such as stoma-related complications. It is necessary to design multidisciplinary intervention programmes, based on scientific evidence, which contain knowledge and practices to promote the resilience process 
together with measures to prevent possible complications. This would allow better adjustment to the disease and a higher HRQL.

\section{References}

Amar, J., Martínez, M., \& Utria, L. (2013). New approach to health considering the resilience. Revista Salud Uninorte, 29(1), 124-133.

Anaraki, F., Vafaie, M., Behboo, R., Maghsoodi, N., Esmaeilpour, S., \& Safaee, A. (2012).

Quality of life outcomes in patients living with stoma. Indian Journal of Palliative Care, 18(3), 176-80.

Baxter, N., Novotny, P., Jacobson, T., Maidl, L., Sloan, J., \& Young-Fadok, T. (2006). A stoma quality of life scale. Diseases of the Colon \& Rectum, 49(2), 205-212.

Benetti, C., \& Kambouropoulos, N. (2006). Affect-regulated indirect effects of trait anxiety and trait resilience on self-esteem. Personality and Individual Differences, 41(2), 341352.

Black, P. (2010). Teaching stoma patients the practical skills for self-care. British Journal of Healthcare Assistants, 4(3), 132-135.

Bobes, J., Bascaran, M., Garcia-Portilla, M., Bousoño, M., Saiz, P., Wallace, D., \& Hidalgo, R. (2001). Banco de instrumentos básicos en psiquiatría clínica. (Psiquiatría, Ed.). Barcelona.

Bonanno, G. a, \& Diminich, E. D. (2013). Annual Research Review: Positive adjustment to adversity--trajectories of minimal-impact resilience and emergent resilience. Journal of Child Psychology and Psychiatry, and Allied Disciplines, 54(4), 378-401.

Bonanno, G., Ho, S., Chan, J., Kwong, R., Cheung, C., Hospital Authority of Hong Kong, ... Wong. (2008). Psychological Resilience and Dysfunction Among Hospitalized Survivors of the SARS Epidemic in Hong Kong: A Latent Class Approach. Health 
Psychology, 27(5), 659-667.

Bowen, D. J., Morasca, A. A., \& Meischke, H. (2003). Measures and correlates of resilience. Women \& Health, 38(2), 65-76.

Burns, R. a., \& Anstey, K. J. (2010). The Connor-Davidson Resilience Scale (CD-RISC): Testing the invariance of a uni-dimensional resilience measure that is independent of positive and negative affect. Personality and Individual Differences, 48(5), 527-531.

Campillo, J., \& Zaragoza, R. V. De. (2014). La calidad de vida de un paciente ostomizado es mayor al año de practicarse la cirugía que a los 6 meses. IV Congreso Nacional de Enfermería en Cirugía.

Cancio López, S., Coca, C., Fernandez, I., Serrano, R., \& Garcia, M. (2014). Estudio coste efectividad de la atención especializada en ostomia. Instituto Antae. Retrieved from http://www.consejogeneralenfermeria.org/docs_revista/EstudioOstomias.pdf

Canova, C., Giorato, E., Roveron, G., Turrini, P., \& Zanotti, R. (2013). Validation of a stoma-specific quality of life questionnaire in a sample of patients with colostomy or ileostomy. Colorectal Disease: The Official Journal of the Association of Coloproctology of Great Britain and Ireland, 15(11), e692-8.

Clauss-Ehlers, C. S. (2008). Sociocultural factors, resilience, and coping: Support for a culturally sensitive measure of resilience. Journal of Applied Developmental Psychology, 29(3), 197-212.

Cohen, J. (1988). Statistical power analysis for the behavioral sciences . . NJ: Lawrence Earlbaum Associates.

Connor, K., \& Davidson, J. (2003). Development of a new resilience scale: the ConnorDavidson Resilience Scale (CD-RISC). Depression and Anxiety, 18(2), 76-82.

Costanzo, E. S., Ryff, C. D., \& Singer, B. H. (2009). Psychosocial adjustment among cancer survivors: findings from a national survey of health and well-being. Health 
Psychology: Official Journal of the Division of Health Psychology, American Psychological Association, 28(2), 147-56.

Dabirian, A., Yaghmaei, F., Rassouli, M., \& Tafreshi, M. Z. (2011). Quality of life in ostomy patients: a qualitative study. Patient Preference and Adherence.

De Frutos, R., Solís, M., Hernando, A., Béjar, P., Navarro, C., Mayo, N., ... Alonso, M. (2011). Calidad de vida de los pacientes con colostomía e ileostomía a corto y medio plazo. Metas de Enfermería, 14(2), 24-31.

Di Gesaro, A. (2012). Self-care and patient empowerment in stoma management. Gastrointestinal Nursing, 10(2), 19-23.

Erlen, J., Stilley, C., Bender, A., Lewis, M. P., Garand, L., Kim, Y., ... Shaler, C. (2011). Personality traits and chronic illness: a comparison of individuals with psychiatric, coronary heart disease, and HIV/AIDS diagnoses. Applied Nursing Research, 24(2), 78-81.

Ferlay, J., Steliarova-Foucher, E., Lortet-Tieulent, J., Rosso, S., Coebergh, J. W. W., Comber, H., ... Bray, F. (2013). Cancer incidence and mortality patterns in Europe: estimates for 40 countries in 2012. European Journal of Cancer, 49, 1374-1403.

Fernández, J. A., Fernández, M., \& Cieza, A. (2010). Los conceptos de calidad de vida, salud y bienestar analizados desde la perspectiva de la Clasificación Internacional del Funcionamiento (CIF). Revista Española de Salud Pública, 84(2), 169-184.

Garcia-Dia, M. J., DiNapoli, J. M., Garcia-Ona, L., Jakubowski, R., \& O’Flaherty, D. (2013). Concept analysis: resilience. Archives of Psychiatric Nursing, 27(6), 264-70.

George, D., \& Mallery, P. (2003). SPSS for Windows step by step: A simple guide and reference. 11.0 update (4th ed.) (4th ed.). Boston.: Allyn \& Bacon.

Geraldo, S., de Almeida, S. A., \& Silveira, M. M. (2014). Quality of life and self-esteem of patients with intestinal stoma. Journal of Coloproctology, 34(4), 231-239. 
Golicki, D., Styczen, P., \& Szczepkowski, M. (2013). Quality of life in stoma patients in Poland: multicentre cross-sectional study using WHOQOL-BREF questionnaire. Przegląd Epidemiologiczny, 67(3), 491.

Grant, M., Baldwin, C., McCorkle, R., Rawl, S., Mohler, M. J., \& Krouse, R. (2007). Applying the mixted method aproach to multisite study of patients with ostomies. Oncology Nursing Forum, 34(1), 204.

Haase, J. E., Kintner, E. K., Monahan, P. O., \& Robb, S. L. (2014). The resilience in illness Model (RIM) Part 1: exploratory evaluation in adolescents and young adults with cancer. Cancer Nursing, 37(3), E1-12.

Harris, B. A., Berger, A. M., Mitchell, S. A., Steinberg, S. M., Baker, K. L., Handel, D. L., ... Pavletic, S. Z. (2010). Spiritual well-being in long-term survivors with chronic graftversus-host disease after hematopoietic stem cell transplantation. The Journal Of Supportive Oncology, 8(3), 119-125.

Herrero, F., Jara, P., \& Rosel, J. (2011). Validación de una escala de evaluacion docente mediante modelado de ecuaciones estructurales multigrupo. (Jaume I, Ed.). Castellón.

Ho, S. M. Y., Ho, J. W. C., Bonanno, G. A., Chu, A. T. W., \& Chan, E. M. S. (2010). Hopefulness predicts resilience after hereditary colorectal cancer genetic testing: a prospective outcome trajectories study. BioMedi Central (BMC) Cancer, 10, 279.

Hou, W. K., Law, C. C., Yin, J., Yiu, ;, Fu, T., \& Kong, H. (2010). Resource Loss, Resource Gain, and Psychological Resilience and Dysfunction Following Cancer Diagnosis: A Growth Mixture Modeling Approach. Health Psychology, 29, 484-495. http://doi.org/10.1037/a0020809

Hu, A., Pan, Y., Zhang, M., Zhang, J., Zheng, M., Huang, M., ... Wu, X. (2014). Factors Influencing Adjustment to a Colostomy in Chinese Patients: A Cross-sectional Study. Journal Of Wound, Ostomy, And Continence Nursing: Official Publication Of The 
Wound, Ostomy And Continence Nurses Society / WOCN, 41(5), 455-459. http://doi.org/10.1097/WON.0000000000000053

INE. (2013). Instituto Nacional de Estadística. Retrieved from www.ine.es

Jansen, F., van Uden-Kraan, C. F., Braakman, J. A., van Keizerswaard, P. M., Witte, B. I., \& Verdonck-de Leeuw, I. M. (2015). A mixed-method study on the generic and ostomyspecific quality of life of cancer and non-cancer ostomy patients. Supportive Care in Cancer: Official Journal of the Multinational Association of Supportive Care in Cancer, 23(6), 1689-1697.

Johnston, M. C., Porteous, T., Crilly, M. A., Burton, C. D., Elliott, A., Iversen, L., ... Black, C. (2015). Physical Disease and Resilient Outcomes: A Systematic Review of Resilience Definitions and Study Methods. Psychosomatics, 56(April), 168-180. http://doi.org/10.1016/j.psym.2014.10.005

Juul, K., \& Prieto, L. (2008). Quality of Life with an Intestinal Stoma. Seminars in Colon and Rectal Surgery, 19(3), 167-173.

Kawasaki, Y., Uchinuno, A., Arao, H., Kobayashi, T., \& Otsuka, N. (2011). Evaluating the self-care agency of patients receiving outpatient chemotherapy. Clinical Journal of Oncology Nursing, 15(6), 668-73.

Krouse, R. S., \& Grant, M. (2003). Health-related quality of life in patients with intestinal stomas. Clinical Therapeutics, 25, D16-D17.

Krouse, R. S., Grant, M., Rawl, S. M., Mohler, M. J., Baldwin, C. M., Coons, S. J., ... Ko, C. Y. (2009). Coping and acceptance: the greatest challenge for veterans with intestinal stomas. Journal of Psychosomatic Research, 66(3), 227-33.

Lam, W. W. T., Bonanno, G. a, Mancini, A. D., Ho, S., Chan, M., Hung, W. K., ... Fielding, R. (2010). Trajectories of psychological distress among Chinese women diagnosed with breast cancer. Psycho-Oncology, 19(10), 1044-1051. 
Lamond, A. J., Depp, C. a, Allison, M., Langer, R., Reichstadt, J., Moore, D. J., ... Jeste, D. V. (2008). Measurement and predictors of resilience among community-dwelling older women. Journal of Psychiatric Research, 43(2), 148-54.

Lee, P. W. H., Kwan, T. T. C., Kwong, D. L. W., Sham, J. S. T., Pow, E. H. N., McMillan, A. S., \& Au, G. K. H. (2007). A prospective study of the impact of nasopharyngeal cancer and radiotherapy on the psychosocial condition of Chinese patients. Cancer, 109(7), $1344-1354$.

Li, C., Rew, L., \& Hwang, S. (2012). The relationship between spiritual well-being and psychosocial adjustment in Taiwanese patients with. Journal Of Wound, Ostomy, And Continence Nursing: Official Publication Of The Wound, Ostomy And Cont, 39(2), 161.

Liao, C., \& Qin, Y. (2014). Factors associated with stoma quality of life among stoma patients. International Journal of Nursing Sciences, 1(2), 196-201.

Lin, H.-C., Wu, C.-H., \& Lee, H.-C. (2009). Risk factors for suicide following hospital discharge among cancer patients. Psycho-Oncology, 18(10), 1038-1044.

Liu, Y., Wang, Z. H., \& Li, Z. G. (2012). Affective mediators of the influence of neuroticism and resilience on life satisfaction. Personality and Individual Differences, 52(7), 833838.

Lü, W., Wang, Z., Liu, Y., \& Zhang, H. (2014). Resilience as a mediator between extraversion, neuroticism and happiness, PA and NA. Personality and Individual Differences, 63, 128.

Luo, B.-J., Qin, H.-Y., \& Zheng, M.-C. (2014). Correlation between social relational quality and hope among patients with permanent colostomies. International Journal of Nursing Sciences, 1(5).

Luthar, S. S., Cicchetti, D., \& Becker, B. (2000). The construct of resilience: a critical evaluation and guidelines for future work. Child Development, 71(3), 543-562. 
Mahjoubi, B., Mirzaei, R., Azizi, R., Jafarinia, M., \& Zahedi-Shoolami, L. (2012). A crosssectional survey of quality of life in colostomates: a report from Iran. Health And Quality Of Life Outcomes, 10, 136.

Marina, O., \& Angarita, V. (2014). Agencia de autocuidado en hipertensos usuarios de un hospital universitario en Cúcuta ( Colombia ) Selfcare agency in hypertensive users of a university hospital in Cucuta ( Colombia ). Salud Uniforme, 30(2), 133-146.

Marquis, P., Marrel, A., \& Jambon, B. (2003). Quality of life in patients with stomas: the Montreux Study. Ostomy/wound Management, 49(2), 48-55.

Mathis, K. L., Boostrom, S. Y., \& Pemberton, J. H. (2013). New developments in colorectal surgery. Current Opinion in Gastroenterology, 29(1), 72-78.

Maydick, D. R. (2014). Individuals with a Permanent Ostomy: Quality of Life and Out-ofPocket Financial Costs for Ostomy Management. Nursing Economic\$, 32(4), 204-218. Mezzich, J. E., Cohen, N. L., Ruiperez, M. A., Banzato, C. E. M., \& Zapata-Vega, M. I. (2011). The Multicultural Quality of Life Index: presentation and validation. Journal of Evaluation in Clinical Practice, 17(2), 357-64.

Min, J., Yoon, S., Lee, C., Chae, J., Lee, C., Song, K., \& Kim, T. (2013). Psychological resilience contributes to low emotional distress in cancer patients. Supportive Care in Cancer, 21(9), 2469-2476.

Molina, Y., Yi, J. C., Martinez-Gutierrez, J., Reding, K. W., Yi-Frazier, J. P., \& Rosenberg, A. R. (2014). Resilience among patients across the cancer continuum: diverse perspectives. Clinical Journal of Oncology Nursing, 18(1), 93-101.

Morin, R. T., Galatzer-Levy, I. R., Maccallum, F., \& Bonanno, G. A. (2017). Do multiple health events reduce resilience when compared with single events? Health Psychology, 36(8), 721-728. http://doi.org/10.1037/hea0000481

O'Connor, G. (2005). Teaching stoma-management skills: the importance of self-care. 
British Journal of Nursing, 14(6), 320-324.

Olbrisch, M. E. (1983). Development and validation of the Ostomy Adjustment Scale. Rehabilitation Psychology, 28(1), 3-12. http://doi.org/10.1037/h0090996

Ong, A. D., Bergeman, C. S., \& Boker, S. M. (2009). Resilience comes of age: defining features in later adulthood. Journal Of Personality, 77(6), 1777-1804.

Peng, L., Zhang, J., Li, M., Li, P., Zhang, Y., Zuo, X., .. Xu, Y. (2012). Negative life events and mental health of Chinese medical students: the effect of resilience, personality and social support. Psychiatry Research, 196(1), 138-141.

Person, B., Ifargan, R., Lachter, J., Duek, S. D., Kluger, Y., \& Assalia, A. (2012). The impact of preoperative stoma site marking on the incidence of complications, quality of life, and patient's independence. Diseases of the Colon and Rectum, 55(7), 783-7.

Pittman, J., Kozell, K., \& Gray, M. (2009). Should WOC Nurses Measure Health-Related Quality of Life in Patients Undergoing Intestinal Ostomy Surgery? Journal of Wound Ostomy \& ..., 36(June), 254-265.

Pittman, J., Rawl, S. M., Schmidt, C. M., Grant, M., Ko, C. Y., Wendel, C., \& Krouse, R. S. (2008). Demographic and clinical factors related to ostomy complications and quality of life in veterans with an ostomy. Journal Of Wound, Ostomy, And Continence Nursing: Official Publication Of The Wound, Ostomy And Continence Nurses Society / WOCN, 35(5), 493-503.

Popek, S., Grant, M., Gemmill, R., Wendel, C. S., Mohler, M. J., Rawl, S. M., ... Krouse, R. S. (2010). Overcoming challenges: life with an ostomy. American Journal of Surgery, 200(5), 640-5.

Prieto, L., Thorsen, H., \& Juul, K. (2005). Development and validation of a quality of life questionnaire for patients with colostomy or ileostomy. Health and Quality of Life Outcomes, 3(1), 62. 
Quiceno, J. M., \& Vinaccia, S. (2011). Resiliencia: una perspectiva desde la enfermedad crónica en población adulta. Pensamiento Psicologico, 9(17), 69-82.

Rowland, J. H., \& Baker, F. (2005). Introduction: resilience of cancer survivors across the lifespan. Cancer, 104(11 Suppl), 2543-8.

Shi, M., Wang, X., Bian, Y., \& Wang, L. (2015). The mediating role of resilience in the relationship between stress and life satisfaction among Chinese medical students: a cross-sectional study. BMC Medical Education, 15(1), 1-7.

Shun, S.-C., Hsiao, F.-H., Lai, Y.-H., Liang, J.-T., Yeh, K.-H., \& Huang, J. (2011). Personality trait and quality of life in colorectal cancer survivors. Oncology Nursing Forum, 38(3), E221-8.

Simmons, K., Smith, J., Bobb, K.-A., \& Liles, L. (2007). Adjustment to colostomy: stoma acceptance, stoma care self-efficacy and interpersonal relationships. Journal of Advanced Nursing, 60(6), 627-35.

Sprangers, M., Te Velde, A., \& Aaronson, N. (1999). The construction and testing of the EORTC colorectal cancer-specific quality of life questionnaire module (QLQ-CR38). European Journal of Cancer, 35(2), 238-247.

Stephenson, L., Wagner, S., \& Bolton, D. (2013). Maximizing patient autonomy to improve outcomes. British Journal of Hospital Medicine, 74(1), 14-17.

Strauss, B., Brix, C., Fischer, S., Leppert, K., Füller, J., Roehrig, B., ... Wendt, T. G. (2007). The influence of resilience on fatigue in cancer patients undergoing radiation therapy (RT). Journal of Cancer Research and Clinical Oncology, 133(8), 511-8.

Sun, V., Grant, M., McMullen K, C., Altschuler, A., Mohler Jane, M., Hornbrook C, M., ... Krouse S, R. (2014). From diagnosis through survivorship: health-care experiences of colorectal cancer survivors with ostomies. Supportive Care in Cancer, 22(6), 15631570. 
Temprado, M. D., Agut, S., \& Collado, E. (2017). The mediating role of resilience in the relationship between personality and adjustment to disease in patients with a drainage enterostomy. Journal of Health Psychology, 135910531668914. http://doi.org/10.1177/1359105316689142

Van Dick, R., Ketturat, C., Häusser, J. A., \& Mojzisch, A. (2017). Two sides of the same coin and two routes for improvement: Integrating resilience and the social identity approach to well-being and ill-health. Health Psychology Open, 4(2), 205510291771956. http://doi.org/10.1177/2055102917719564

Vera, E. J., Borraz, J. R., Domínguez, J. A., Mora, L. M., Casado, S. V, \& González, J. A. (2014). Prevalencia de patologías crónicas y factores de riesgo en población penitenciaria española. Revista Española de Sanidad Penitenciaria, 16(June 2013), $38-47$.

Waaktaar, T., \& Torgersen, S. (2010). How resilient are resilience scales? The Big Five scales outperform resilience scales in predicting adjustment in adolescents. Scandinavian Journal of Psychology, 51(2), 157-63.

Weston, S., \& Jackson, J. (2014). Identification of the healthy neurotic: Personality traits predict smoking after disease onset. Journal of Research in Medical Sciences.

Williams, J. (2012). educational theory in practice, 21(13).

Wu, W., Tsai, S., Liang, S., Liu, C., Jou, S., \& Berry, D. (2015). The Mediating Role of Resilience on Quality of Life and Cancer Symptom Distress in Adolescent Patients With Cancer. Journal of Pediatric Oncology Nursing, (365). 
Table 1

Sociodemographic and clinical characteristics of the sample

\begin{tabular}{|c|c|c|c|c|c|}
\hline \multicolumn{2}{|c|}{ Sociodemographic variables } & $\%$ & Clinical variables & & $\%$ \\
\hline \multirow[t]{3}{*}{ Gender } & & & Medical diagnosis & & \\
\hline & Males & 64 & & Colon cancer & 85.6 \\
\hline & Females & 36 & & Inflammatory diseases & 9.6 \\
\hline \multicolumn{3}{|c|}{ Marital Status } & & Others & 4.8 \\
\hline & With a Partner & 83.2 & Type of Ostomy & & \\
\hline \multirow{6}{*}{ Children } & Without a Partner & 16.8 & & Colostomy & 81.6 \\
\hline & & & & Ileostomy & 18.4 \\
\hline & Without children & 10.4 & Timeline & & \\
\hline & With children & 89.6 & & Temporary & 33.6 \\
\hline & & & & Permanent & 66.4 \\
\hline & & & & Yes & 16.8 \\
\hline \multirow[t]{5}{*}{ Age } & & & & No & 83.2 \\
\hline & $>50$ & 10.4 & Complications & & \\
\hline & $50<70$ & 48.8 & & Yes & 18.8 \\
\hline & $<70$ & 40.8 & & No & 83.2 \\
\hline & & & Care autonomy & & \\
\hline \multirow[t]{6}{*}{ Education } & & & & Yes & 79.8 \\
\hline & No education & 28.8 & & No & 20.2 \\
\hline & Primary education & 44 & & & \\
\hline & $\begin{array}{l}\text { Non-compulsory } \\
\text { secondary education }\end{array}$ & 17.6 & & & \\
\hline & University & 8.8 & & & \\
\hline & Others & .8 & & & \\
\hline \multicolumn{6}{|c|}{ Employment Status } \\
\hline \multicolumn{6}{|c|}{ Retired } \\
\hline & Self-employed & 1.6 & & & \\
\hline & Employed & 9.6 & & & \\
\hline & Others & 12 & & & \\
\hline \multicolumn{6}{|l|}{ Income } \\
\hline & 0 & 4.8 & & & \\
\hline & $0-6,000$ & 60.8 & & & \\
\hline & $6,000-12,000$ & 12 & & & \\
\hline & $12,000-18,000$ & 16 & & & \\
\hline & $>18,000$ & 6.4 & & & \\
\hline
\end{tabular}


Table 2

Intercorrelations of Pearson Correlation, Means and Standard Deviations on scores above 100 points on the CD-RISC, QLI and Stoma-QoL scales $(N=125)$

Variable Resilience (CD_Risc) General Quality of Life (QLI) Stoma-Qol Quality of Life (Total)

Resilience (CD_Risc) $----$

General Quality of Life (QLI) $.497^{\star * * *}$

Stoma-Qol Quality of Life (Total) $.452^{\star * \star *}$ $.240^{\star \star \star}$

Mean (M)

79.57

77

80.5

Standard Deviation (SD)

12.55

11.20

13.5

Note: $\mathrm{N}=$ number of patients

$* p<.10 . * * p<.05 . * * * p<.01 . * * * * p<.001$ 
Table 3

a) Parametric and non-parametric tests Student $t$ for independent samples QLI

\begin{tabular}{|c|c|c|c|c|c|c|c|}
\hline & \multicolumn{2}{|c|}{ Levene test } & \multicolumn{5}{|c|}{$\mathrm{t}$ test for equality of means } \\
\hline & \multirow[t]{2}{*}{$\mathrm{F}$} & \multirow[t]{2}{*}{$\mathrm{p}<.05$} & \multirow[t]{2}{*}{$\mathrm{t}$} & \multirow[t]{2}{*}{ df } & \multirow[t]{2}{*}{$\mathrm{p}<.05$} & \multicolumn{2}{|c|}{$95 \% \mathrm{CI}$} \\
\hline & & & & & & Inferior & Superior \\
\hline Complications with the stoma & 2.167 & .144 & 1.968 & & $102.033 *$ & .59787 & 14.31709 \\
\hline Care autonomy & 13.516 & .001 & 3.464 & & $121.001 * * *$ & 3.42130 & 12.55092 \\
\hline
\end{tabular}

b) Non-parametric tests for independent samples Stoma-QOL and CD-Risc

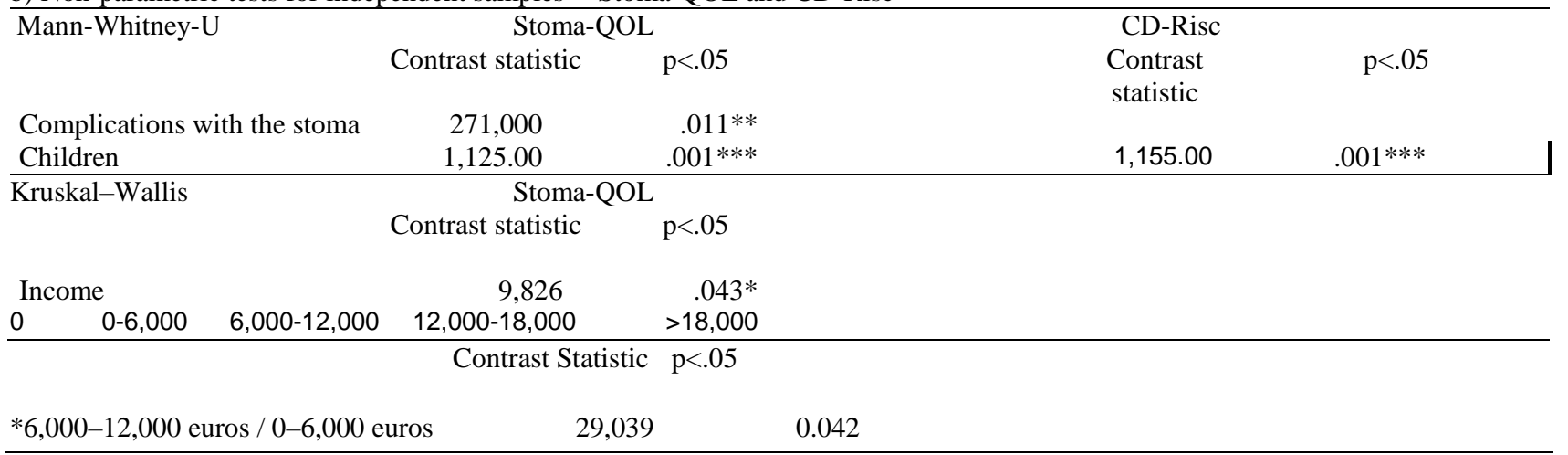

$* \mathrm{p}<.05 . * * \mathrm{p}<.01 . * * * \mathrm{p}<.001$ 
Table 4

Multiple regression analysis predicting Quality Of life with sociodemographic, clinical and resilience variables

\begin{tabular}{|c|c|c|c|c|c|}
\hline & Model & $\begin{array}{c}\mathrm{R}^{2} \\
\text { adjusted }\end{array}$ & $\begin{array}{l}\text { Standardised } \\
\text { coefficients } \\
\text { Beta }\end{array}$ & $\begin{array}{l}\text { Standar } \\
\text { error }\end{array}$ & $F(p)$ \\
\hline 1 & $\begin{array}{c}\text { (Constant) } \\
\text { Resilience (CD-Risc) }\end{array}$ & 191 & .425 & 8.403 & $\begin{array}{c}29,865 \\
(p<0.000)\end{array}$ \\
\hline 2 & $\begin{array}{c}\text { (Constant) } \\
\text { Resilience (CD-Risc) } \\
\text { Complications with the stoma }\end{array}$ & .224 & $\begin{array}{l}.384 \\
-.216\end{array}$ & 8.234 & $\begin{array}{c}18.564 \\
(p<0.000)\end{array}$ \\
\hline 3 & $\begin{array}{c}\text { (Constant) } \\
\text { Resilience (CD-Risc) } \\
\text { Complications with the stoma } \\
\text { Income }\end{array}$ & .244 & $\begin{array}{l}.395 \\
-.235 \\
-.200\end{array}$ & 8.124 & $\begin{array}{c}14.133 \\
(p<0.000)\end{array}$ \\
\hline
\end{tabular}

$* \mathrm{p}<.05 . * * \mathrm{p}<.01 . * * * \mathrm{p}<.001$ 